\title{
Polycentric Employment Growth and the Commuting Behaviour in Benin Metropolitan Region, Nigeria
}

\author{
Monday Ohi Asikhia ${ }^{1} \&$ Ndidi Felix Nkeki ${ }^{1}$ \\ ${ }^{1}$ Department of Geography and Regional Planning, University of Benin, Benin City, Nigeria \\ Correspondence: Ndidi Felix Nkeki, Department of Geography and Regional Planning, University of Benin, \\ Benin City, Nigeria. E-mail: fil4all@yahoo.co.uk
}

Received: January 15, 2013 Accepted: March 7, 2013 Online Published: March 21, 2013

doi:10.5539/jgg.v5n2p1 URL: http://dx.doi.org/10.5539/jgg.v5n2p1

\begin{abstract}
The paper investigates the emerging pattern of journey to work traffic that characterises the employment centres of a fast growing African city with reference to the case of Benin region, Nigeria. This is achieved by identifying and extracting the significant employment centres of the region. On the one hand, factor analysis and Getis-Ord statistic were systematically used to identify the spatial configuration of the region's employment. Regression models on the other hand, were used to estimate the relationship that exists between job decentralisation and travel behaviour. Factor analysis and Getis-Ord statistic identified four significant employment clusters in the region. Multivariate and bivariate regression models were further used to explore the dynamics of commuting behaviour in response to decentralisation of employment centres. It is found that employment spatial structure exerts significant influence on all dimensions of commuting pattern of the region. The result shows that decentralisation of jobs in the metropolis has led to a reduction in commuting times, travel distance and significantly influence the modal choice of commuters.
\end{abstract}

Keywords: Benin metropolitan region, decentralisation, metropolitan spatial structure, commuting pattern, hot-spot analysis, factor analysis, binary logit model

\section{Introduction}

The current debate on metropolitan spatial structure is that the processes of urban growth and development initiate the re-location of employment clusters inside the CBD to emerging employment centres in the edge of the city. This spatial re-organisation establishes competition for traffic between the traditional CBD and the evolving sub-centres and this as revealed by empirical literatures in developed countries affect commuting behaviour. For example, many researchers have shown that the re-location of employment location from the traditional core centre to sub-centres in the periphery tend to reduce mass transit performance and promotes the use of private cars for commuting (Schwanen et al., 2001; Cervero \& Wu, 1998; Cervero \& Landis, 1992). Others have suggested that this spatial rearrangement shortens travel times and distance (Susilo \& Maat, 2007; Crane \& Chatman, 2003; Levinson \& Kumar, 1994; Giuliano \& Small, 1993; Dubin, 1991; Gordon et al., 1991; Gordon et al., 1989). This is but one side of the debate. Nevertheless, many empirical studies have drawn opposite conclusion (Yang, 2005; Schwanen et al., 2004, 2003, 2001; Cervero \& Wu, 1998; Ewing, 1997; Cervero, 1996; Newman \& Kenworthy, 1989). In many African cities, the link between polycentric employment growth and travel behaviour is poorly understood.

However, a review of related literature confirms that the recent investigations on metropolitan spatial structure and commuting are focused on European (Ham et al., 2001; Schwanen et al., 2001), American (McMillen, 2001; Cervero \& Wu, 1998), Asian (Hakim \& Parolin, 2009; Alpkokin et al., 2005) and Australian (Parolin, 2006) cities. There is a striking research gap regarding African cities. The purpose of this paper therefore, is to identify the employment spatial structure of BMR and how such structure affects commuting behaviour. This knowledge would help to influence or provide a suitable platform for decision making, with respect to formulating transportation and land use development policy response to improve the current demand in a challenging traditional metropolis like Benin. 


\section{Background Literature}

The issue of metropolitan spatial structure and commuting to work has raised widespread debates and series of assumptions. Basically, assumptions about the relationship between metropolitan structure and travel behaviour have found their way into planning concepts and policies. A good example is the new urbanism movement, which advocates new and sustainable urban design principles to cope with urban sprawl, reduces traffic congestion and over reliance on private mode of transport in everyday activities.

However, some scholars have argued that decentralisation of jobs in a metropolis tends to result in shorter trips but higher shares of private transport usage (Crane \& Chatman, 2003; Levinson \& Kumar, 1994; Gordon et al., 1989, 1991; Giuliano \& Small, 1993; Gordon \& Wong, 1985). This is because jobs will move closer to the workers creating a spatial balance between employment location and residential location which leads to reduction in distance and time of commuting to work.

In favour of the co-location hypothesis, Gordon et al. (1989) studied the influence of metropolitan spatial structure on travel time and their result shows that as traffic congestion builds near the core region, some centrally located employers respond by relocating from the CBD to a place closer to their workers and customers, causing some of this employment to become clustered in sub-centres. They further observed that the transition of a metropolitan area from a monocentric to a polycentric configuration, average commuting times and congestion levels are reduced. Crane and Chatman (2003) used a different approach to study the impact of metropolitan structure on average commute length. It was concluded that decentralisation of employment reduces commuting distance. Guth et al. (2009) determined the effects of employment suburbanisation on commuting pattern in German city regions from 1987-2007. They compared two monocentric regions against two polycentric regions to determine how different urban spatial structures affect commuting. They concluded that polycentric metropolitan regions tends to be more travel-efficient compared to monocentric regions.

Other scholars have presented contradicting research conclusions (Cervero, 1996; Schwanen et al., 2004; Yang 2005; Parolin, 2006). For instance, Cervero and Wu (1998) argued that in the San Francisco Bay area both commute times and distances rose after an increase in the degree of polycentrism. Schwanen et al. (2003) revealed that the co-location hypothesis is not applicable in the European situation. They argued that the Europeans tend to get more attached to the places where they reside. Snellen et al. (2005) found no link between urban structure and kilometres travelled. Schwanen et al. (2004) concluded that commute distances and times for private car drivers are longer in most polycentric regions than in monocentric urban areas.

With reference to the influence of decentralisation on travel mode, a number of scholars have shown that decentralisation of employment location into suburban areas not only shortens the length of travel but also promotes the use of private transport. As a result, transit performance is degraded (Schwanen et al., 2004, 2001; Cervero \& Wu, 1998). Izraeli and McCarthy (1985) revealed that modal choice for commuters is strongly affected by the structure of the metropolitan area. A contrary conclusion is presented by Kitamura et al. (2003) and Bollote (1991).

\section{Study Region}

Rapid urban territorial expansion of Benin Metropolitan Region (BMR), with respect to morphology and socio-economic activities, had been significantly driven by population growth. Over the years, the region has witnessed a tremendous growth in population and areal/coverage (Onokerhoraye, 1978). Evidence from previous empirical studies have shown that in the last 54 years (1952-2006), BMR has witnessed an enormous increase of over 1919.7 percentage growth in its population (Nkeki, 2010). Based on the 2006 population census, the region's population is $1,085,676$. The rapid areal expansion in its territory is attributable to the existing trunk transport corridors connecting the urban core of Benin to the metropolitan edges and beyond (Figure 1).

However, these developments have equally ensured direct inflow of investment to the region. The investments, which are focused basically on finance, trading, manufacturing, education, health, services, property development, transportation and a plethora of other micro-investments and businesses have substantially influenced the spatial arrangement of employment in BMR. In the ancient time, Benin region was prominent and regarded as the centre for trade in such products as ivory, pepper, wood works and bronze art materials. Later, the region became prosperous in the production of agricultural crops such as yams, cassava, corn, rubber, palm oil and timber.

Recently, improvement in education (which involves the establishment of a federal university and many other private elementary and high schools) and the diversification of commercial activities transformed the region from agro-based to a growth pole of commercial, administrative, educational and corporate activities. The 
urbanisation of Benin region has not only led to the rapid concentration of these ranges of modern activities but has also ensured that agricultural activities must give way to urbanisation. This is often seen in the manner in which farmlands are converted to site for residential, school, financial, administrative and shopping complexes.

Replacement of initial land-use pattern started from the Central Business District (CBD), which is the origin of residential clusters in the region. The economic pressure that followed the rapid urbanisation of the area, initiated a large scale replacement of residential buildings and relocation of residents from the urban core to the adjoining peripheral areas. Such large scale replacement has in the same proportion, commercialised the core area and transformed it into a "business boom" axis. This active centre is fast penetrating the periphery from the urban core, mainly along the radial trunk corridor roads. However, private developers and investors had converted substantial parts of the peripheral land in BMR into high density residential areas. Investment in the banking, trading and service industries is a prerequisite to the expansion of the region, especially the urban core and investment in these sectors is concentrated within the CBD. This is directly attributed to the increasing demand for land in the CBD, which in turn increased land prices and put pressure in residents living in the core centre. This pressure forces the residents to give up their lands and relocate to the edge of the city where land and rent are relatively cheap.

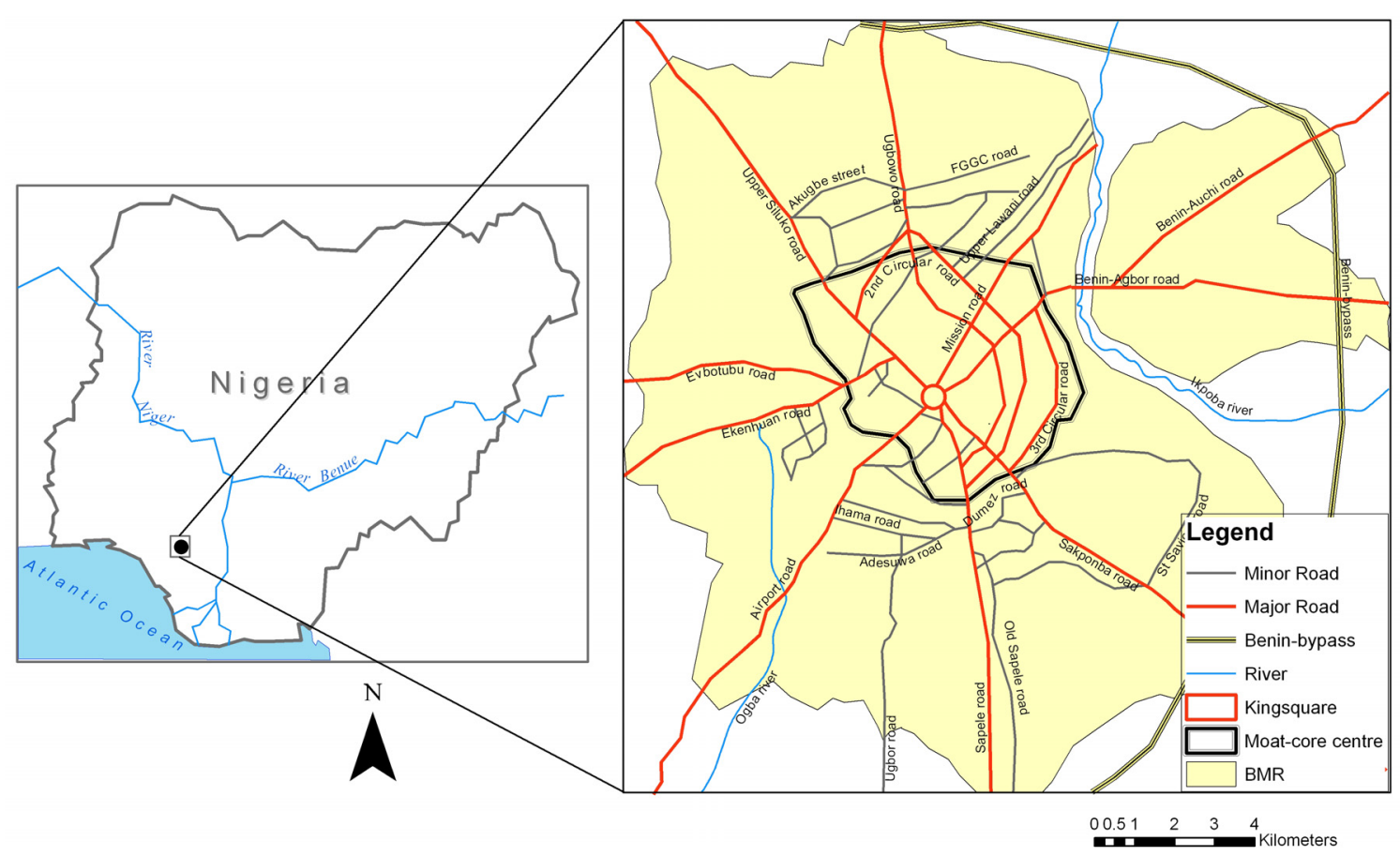

Figure 1. Benin metropolitan region (study area)

The sprawl of residential buildings in the peripheral areas, particularly along trunk road network were followed by vital amenities such as schools, hospitals, markets, shopping centres and other trading activities. These areas are found along the trunk corridor route of Aduwawa-Agbor road, Sapele road, Sakponba road and Ugbowo-Lagos road. While the peripheral zone of BMR is fast developing its residential land-use, the core axis is rapidly being transformed by market forces into large commercial centre. Overall, the region exhibits an interesting character with regard to it expansion pattern. As residential land-use spreads radially further into the adjoining periphery, engulfing initial agricultural land-use, the commercial land-use has in turn expanded radially and rapidly engulfing contiguous residential areas.

The urban core which had metamorphosed from purely residential area to high intensity commercial axis has become a prominent centre of employment. Over the years, the urban core has been known to have sustained dominance with respect to the attraction of journey to work traffic. BMR exhibits a monocentric spatial structure; composed of a strong single CBD surrounded by concentric residential zones that are linked to the urban core by radial corridor road network. Whether BMR will follow the fundamental assumption of the monocentric model that the CBD is the only existing source of employment can be questioned. This is based on the emerging trend 
in literature that cities are evolving from purely monocentric to essentially polycentric employment spatial structure (Guth et al., 2009; Alpkokin et al., 2008; Aguilera \& Mignot, 2004; Giuliano \& Small, 1991). Though the 1992 Benin master plan considered the city as monocentric in structure, it has not been empirically investigated in any detail whether the region is purely monocentric or perhaps, other employment sub-centres have emerged over the years and how journey to work is relatively affected.

\section{Methodology}

To analyse the effects of the dispersal of employment centres on travel behaviour, this study relies on data generated with questionnaire from a home based survey, conducted in the last quarter of 2010 and first quarter of 2011. It was necessary to conduct a home based questionnaire survey due to the fact that the available national census data which is the major source of information for the country does not contain commuting trip data or the spatial distribution of employment and there is no household travel and employment survey database for the region. The unavailability of spatial and non-spatial data is the substantive reason while empirical studies on built environment and travel behaviour in the country are limited. In most advanced countries (in America, Europe, Australia and Southeast Asia), census data is well disaggregated into smaller entities such as census tracts, traffic analysis zones, travel zones etc. and other sources of travel data exist which are sometimes use independently or to compliment the national census data. In the case of a developing country like Nigeria, national census data is compiled and aggregated into a larger component such as county level, senatorial district, state level and geo-political zones.

BMR is defined by its continuously built-up area comprises three counties (Oredo, Ikpoba-Okha and Egor). It extends from the central core at Oredo County to the northwest and northeast end of the metropolis and has since spread over a substantial part of Ovia Northeast County and Uhunmwode County in the northwest and northeast angle respectively. Along the corridor of Sakponba and Sapele roads in the southeast, it has extended as far as the by-pass (Figure 1). However, this contiguous spread and encroachment of BMR into sounding territories makes it difficult to extract the actual household employment figures from the available census data. Notwithstanding, previous estimate has shown that there are roughly 200000 households in the region.

\subsection{Data}

The data used in this study was extracted from a self-supervised administered questionnaire survey in BMR. The original sample for the study is composed of 2000 households from the study region (such sample size was selected due the cost and time-based implication of conducting larger survey in Nigeria). The segmentation is such that 200 questionnaires were administered in each of the stratified randomly selected location-neigbourhood in BMR. To ensure objectivity in sample size selection and a substantial reduction of sampling error, not less than 5 percent of households in each of the selected neighbourhoods were drawn. Out of the 2000 administered questionnaires, 1706 were considered valid (85.3 percent response rate), these include the total number retrieved, and those with bias and non-response were removed. The data is organised into two datasets: household dataset, containing information on households zone address, household monthly income and expenditure type of job and household size; commuting trip dataset, containing details of trips made by heads of household to work including the trips origin zone and address, departure time, travel mode, arrival time, destination zone address and travel distance. Household in this paper is a person or group of persons living together at an address within the study area that are or is catered for from one particular source and recognised themselves as a social unit with a head of household. The region is stratified into five major planning zones (PZs)-the central core, the northeast, northwest, southeast and southwest zones. Beside the central core, other PZs are located in the region's periphery. PZ is defined in this paper as a metropolitan zoning system for the purpose of development and accessibility planning. The PZs were delineated based on the catchment areas along the trunk corridor roads that show strong core-periphery relationship. This is done in such a way that each peripheral zone has two trunk corridor roads that links the regions core centre. The core centre PZ is separated from the periphery's PZs by the inner moat. Overall, a total of 55 neigbourhoods were delineated in the region. Neigbourhood in this context is delineated and defined as a particular named-area/areal containing not less than 3 streets and enclosed or almost enclosed by major roads. However, 2 neigbourhoods were randomly drawn from each of the PZs; this is to avoid the clustering of sample sites in one PZ. The selected neigbourhoods include; Esigie and Oguola (located in the central core of 21 neigbourhoods), Oregbeni and Agbor-park (located in the northeast zone of 8 neigbourhoods), Iduowinna and Ogida (northwest zone of 10 neigbourhoods), Ekae and Etete (southwest zone of 7 neigbourhoods) and St. Maria Goretti and Ugbeku (southeast zone of 9 neigbourhoods). In addition, hard copy maps which were later digitalised within the geo-processing ability of the ArcGIS 9.3 and stored in geographic information system (GIS) format were obtained from the ministry of Lands and Survey. These maps include road network and the various neigbourhood limit of the region. 


\subsection{Defining Employment Centres}

Identification of employment centres has become increasingly fundamental and paramount in recent empirical studies of metropolitan spatial structure as a result of the pervasiveness of sub-centres outside the urban core in most contemporary cities of the world (Hakim \& Parolin, 2009). The increasing popularity is based on the fact that the concentration of employment centres has become a major deterministic indicator of urban polycentricity and monocentricity. However, many studies have defined employment centres utilising a variety of approaches. The most common method used is the one proposed by Giuliano and Small (1991) referred to as the minimum density thresholds. Despite its popularity, the method has been criticised for choosing arbitrary thresholds to determine employment sub-centres (Anas et al., 1998). To avoid this weakness, this paper utilised an alternative approach which involves the use of exploratory spatial data analysis (ESDA) to identify centres of employment. ESDA has been chosen by many other researchers to identify employment centres (Rodriguez-Gamez \& Dall'erba, 2012; Hakim \& Parolin, 2009; Baumont et al., 2004) for its efficiency and flexibility.

In this paper, the approach used in defining employment centres is divided into two steps. First, factor analysis was used to group job industry types into components so as to ascertain whether each extracted employment centre has unique type of job industry or industries peculiar to it and to investigate the association that exist between employment sectors. A total of 9 job industry categories were entered into factor analysis. The variables used are the total number of employment by job industry categories from the 5 PZs of BMR. 3 components were significantly retained and these divulged the co-location behaviour of the various employment sectors in the region. The number of factors with high loading values in each component shows the job industry categories that co-locate and exhibit positive association. This provided a platform for naming each employment cluster with respect to the prominent and character of the job industry types.

In the second step, the resulting factor scores then assisted in the calculation of the Gi* statistic to extract significant hot-spots. This is achieved with a spatial contiguity (first order) weight matrix. The hot-spot analysis was calculated and mapped with the ArcMap-ArcInfo extension under the spatial statistics tools in the ArcTool box. In order to determine the statistical significance of the $\mathrm{Gi}^{*}$ score, it is compared to the range of values for a particular confidence level. At a confidence level of $0.05 \mathrm{a} \mathrm{Gi}^{*}$ score is set to equal to 1.65 under a one tailed-test to be statistically significant. Under a two tailed-test, it is set to equal to 1.96 to be statistically significant. This study adopts $0.05(95 \%)$ confidence levels from a two-tailed normal distribution. Statistically significant employment centre is defined by $\mathrm{Gi}^{*}$ score $>1.96$.

\subsection{Analytical Techniques}

The empirical analysis in this study, involve the identification of employment centres in BMR and the statistical estimation of the influence which the identified configuration exert on travel times, distance and mode choice. ESDA and factor analysis were combined to extract vital structure. ESDA includes two basic local statistics, these are Local Moran's I and Local Getis-Ord Gi* developed by Anselin (1995) and Ord and Getis (1995) respectively. ESDA provides the platform for extracting local pockets of spatial dependence that may be ignored when using global statistics. Getis-Ord Gi* for hot-spot analysis is capable of not only identifying but also quantitatively characterising local patterns of spatial dependence or autocorrelation at multiple scales.

Getis-Ord Gi ${ }^{*}$ statistic is adopted in this paper with a slight modification of the ordinary composition. Instead of using employment distribution across the region directly to calculate the Gi* statistic, co-location of employment sectors across the region is first identified by applying factor analysis to the zonal figure of the sampled employment in the study region for each of the 9 employment categories highlighted by the home interview survey. The resulting factor scores then entered into the hot-spot analysis to identify significant clusters relating to each factor. The local $\mathrm{Gi}^{*}$ as presented by Rogerson (2001) takes the form

$$
G_{i}^{*}=\frac{\sum_{j} w i j(d) x_{j}-W_{i}^{*} \bar{x}}{s\left\{\left(n S_{1_{i}}^{*}-W_{i}^{* 2}\right) /(n-1)\right\}^{1 / 2}}
$$

Where $s$ is the sample standard deviation of the $x$ values, wij(d) is a weight matrix element defining neighbourhood relationship between $i$ and $j$ which is measured by the distance $(d)$ between them and $n$ is the number of observations.

$$
\left.\begin{array}{c}
\boldsymbol{W}_{\boldsymbol{i}}^{*}=\sum_{j} w_{i j}(d) \\
\boldsymbol{S}_{1_{i}}^{*}=\sum_{j} w_{i j^{2}}
\end{array}\right\}
$$


The spatial weight of the matrix is equal to 1 if neigbourhood $j$ has a contiguous distance relationship with neigbourhood $i$ and 0 if otherwise.

However, the identified employment centres were subjected to further analysis by applying bi-variate statistical techniques. Binary logit model was used to estimate the effect and make predictions concerning the relationship between the identified employment configurations and commuting mode choice of travel, distance within the region and some socio-economic factors. The binary logit model has been used by numerous researchers to model choice behaviour among two set of independent alternatives (Guoqiang \& Wang, 2012; Muley et al., 2009; Daniel, 1973; Miklius et al., 1976). The model was adopted in this study as opposed to other choice models (nested logit model and multinomial logit model) because two general travel modes (public vs. private) are investigated. Specifically, public mode includes public buses and commercial motorbike while private mode includes car, private motorbike and walk. The variable used for the model is shown in Table 1.

Table 1. Variables for binary logit model

\begin{tabular}{|c|c|c|}
\hline Variable & Type & Coding \\
\hline \multicolumn{3}{|l|}{ Dependent } \\
\hline \multirow[t]{2}{*}{ Preferred travel mode } & Binary response & $0=$ public \\
\hline & & $1=$ private \\
\hline \multicolumn{3}{|l|}{ Independent } \\
\hline \multirow[t]{4}{*}{ Age } & Categorical response & $1=<25 \mathrm{yrs}$ \\
\hline & & $2=(25-45 \mathrm{yrs})$ \\
\hline & & $3=(46-65 y r s)$ \\
\hline & & $4=(>65 \mathrm{yrs})$ \\
\hline \multirow[t]{2}{*}{ Gender } & Categorical response & $0=$ male \\
\hline & & $1=$ female \\
\hline \multirow[t]{4}{*}{ Income } & Categorical response & $1=(<® 50000)$ \\
\hline & & 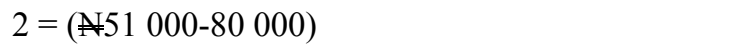 \\
\hline & & $3=(\$ 81000-110000)$ \\
\hline & & $4=(>\$ 110000)$ \\
\hline \multirow[t]{2}{*}{ Car ownership } & Categorical response & $0=$ yes \\
\hline & & $1=$ no \\
\hline \multirow[t]{3}{*}{ Employment centre } & Categorical response & $1=$ heterogeneous job centre \\
\hline & & $2=$ research institution job centre \\
\hline & & $3=$ agricultural and manufacturing job mixed centre \\
\hline \multirow[t]{5}{*}{ Travel distance } & Categorical response & $1=$ less than $1 \mathrm{~km}$ \\
\hline & & $2=1-3 \mathrm{~km}$ \\
\hline & & $3=4-6 \mathrm{~km}$ \\
\hline & & $4=7-9 \mathrm{~km}$ \\
\hline & & $5=$ over $10 \mathrm{~km}$ \\
\hline
\end{tabular}

The sign ( $($ ) represents Nigeria Naira

Moreover, linear regression model was employed to determine the influence which job dispersal exhibit on travel times. The variables used in the model includes journey to work times in minutes-dependent variable, disaggregated employment clusters (i.e. 1 if employment is in the core centre and 0 if in other peripheral centres)-predictor 1, journey to work distance in kilometre-predictor 2 and commuting mode choice-predictor 3 . The statistical package for social science (SPSS) 16.0 and ArcGIS 9.3 were used to calculate the factor analysis, regression models and hot-spot analysis respectively. 


\section{Empirical Results}

The Home interview survey data show that the 3 major industry categories are found in the region. These include primary, secondary and tertiary industry categories. Overall, the primary industry type accounted for 6.1 percent of the total sampled jobs in the region. Secondary industry type accounted for 8.3 percent and tertiary accounted for 85.6 percent. The core centre holds almost half of the total sampled jobs in the metropolis with a zonal percentage of 49.5 ( 844 jobs). Next to this, is the northwest PZ (Ogida-Ugbowo) with a percentage of 19.6 (335 jobs). This is followed by northeast PZ (Aduwawa-Ikpoba hill) which accounted for 14.9 (255 jobs) percent. Next to this, is the southeast PZ (Sakponba-Sapele road) with a zonal percentage of 11.7 (200 jobs) and the southwest PZ (Airport-Ekenhuan road) accounted for 4.2 (72 jobs) percent. The spatial distribution of employment based on the survey is shown in Figure 3.

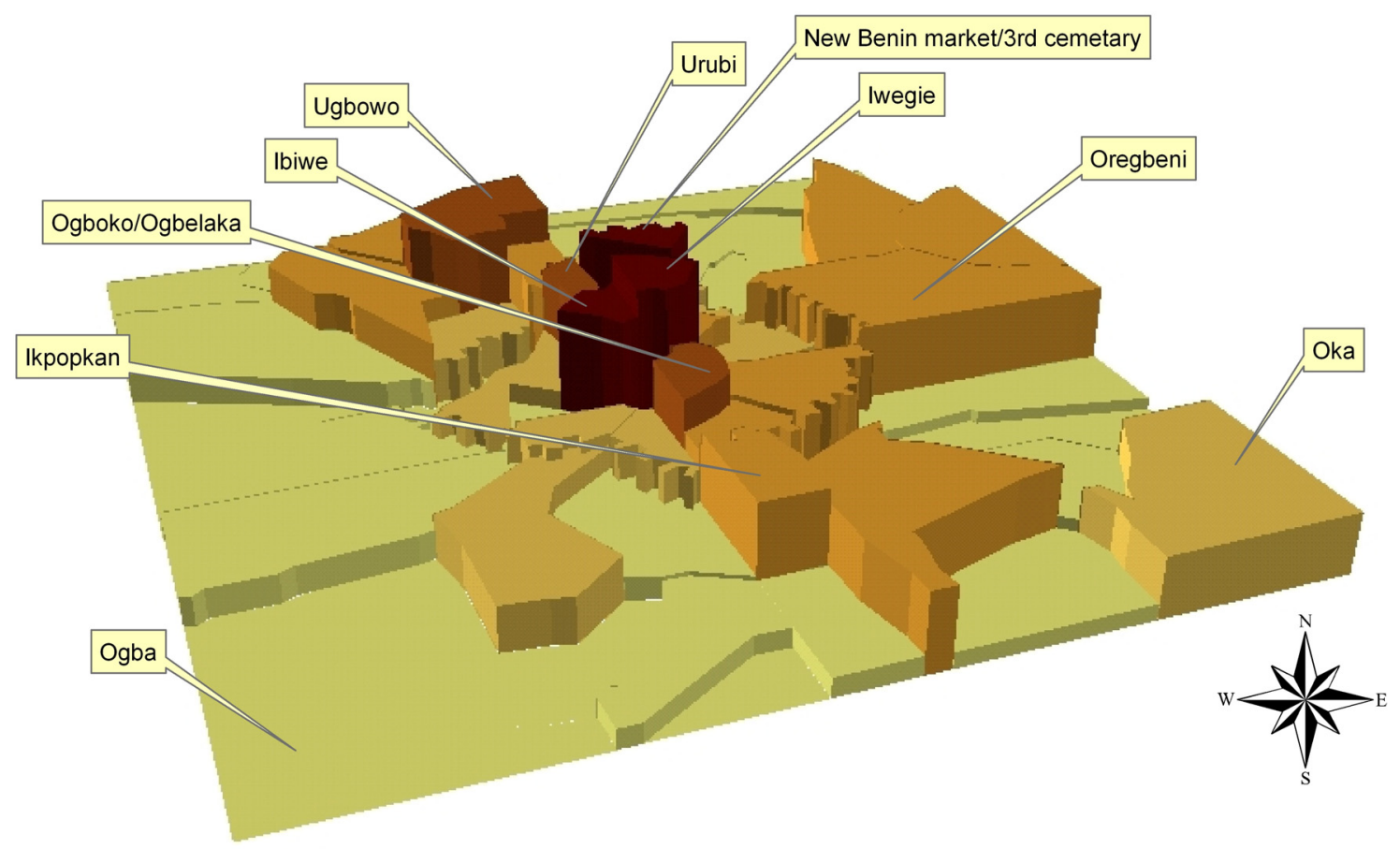

Figure 3. The spatial distribution of employment in Benin metropolitan region. This is based on sample data for the region

\subsection{Identification of Employment Centres}

The relationship between journey to work traffic and employment centres cannot be effectively determined without identifying the employment structural configuration of the urban region. To determine this, factor analysis and hot-spot statistic were used to delineate and identify significant employment clusters in the region. The definition of employment hot-spot in this study begins with identifying the co-location of jobs by industry type across BMR. There are no agreed criteria on deciding the number of factors to retain; Field (2005) suggested two major rules to guide such decision. The first rule is to retain components with eigenvalues greater than one. The second rule is to plot the eigenvalues on the vertical axis and the factor number on the horizontal axis of a scree plot. Then the scree plot is inspected to locate a point at which it flattens out; such a feature implies that the additional factors do not contribute much to the explanation of variability in the dataset (Rogerson, 2001, p. 195). 
Table 2. Eigenvalues for component scores

\begin{tabular}{|c|c|c|c|c|c|c|c|c|c|}
\hline \multirow{2}{*}{ Component } & \multicolumn{3}{|c|}{ Initial Eigenvalues } & \multicolumn{3}{|c|}{$\begin{array}{c}\text { Extraction Sums of Squared } \\
\text { Loadings }\end{array}$} & \multicolumn{3}{|c|}{$\begin{array}{c}\text { Rotation Sums of Squared } \\
\text { Loadings }\end{array}$} \\
\hline & Total & $\begin{array}{c}\% \text { of } \\
\text { Variance }\end{array}$ & Cumulative \% & Total & $\begin{array}{c}\% \text { of } \\
\text { Variance }\end{array}$ & Cumulative \% & Total & $\begin{array}{c}\% \text { of } \\
\text { Variance }\end{array}$ & Cumulative \% \\
\hline 1 & $5.048 * *$ & 56.090 & 56.090 & 5.048 & 56.090 & 56.090 & 4.482 & 49.796 & 49.796 \\
\hline 2 & $2.217 * *$ & 24.637 & 80.727 & 2.217 & 24.637 & 80.727 & 2.359 & 26.213 & 76.009 \\
\hline 3 & $1.174 * *$ & 13.040 & 93.767 & 1.174 & 13.040 & 93.767 & 1.598 & 17.758 & 93.767 \\
\hline 4 & .561 & 6.233 & 100.000 & & & & & & \\
\hline 5 & $9.014 \mathrm{E}-16$ & $1.002 \mathrm{E}-14$ & 100.000 & & & & & & \\
\hline 6 & $4.316 \mathrm{E}-16$ & $4.796 \mathrm{E}-15$ & 100.000 & & & & & & \\
\hline 7 & $2.595 \mathrm{E}-16$ & $2.884 \mathrm{E}-15$ & 100.000 & & & & & & \\
\hline 8 & $1.294 \mathrm{E}-17$ & $1.438 \mathrm{E}-16$ & 100.000 & & & & & & \\
\hline 9 & $-7.812 \mathrm{E}-17$ & $-8.680 \mathrm{E}-16$ & 100.000 & & & & & & \\
\hline
\end{tabular}

**Retained factor components with eigenvalues greater than one.

Based on the first rule, the three factors with eigenvalues greater than one were retained. These explained about 94 percent of the variation in the dataset (Table 2). The rotated component matrix for the three factors is shown in Table 3. The result of factor analysis revealed that factor 1 is positively associated with employment in finance, government, health, wholesale and retail, services, transportation and communication. Basically, factor 1 represents areas with higher job diversity for the number of industries represented in the factors. In fact, factor 1 is called heterogeneous employment centre and it depicts the core centre because it loads high on such job industries that are commonly concentrated in and around the CBD. Factor 2 is highly positively associated with employment in health, education and to a lesser extent, agriculture, transportation and communication. Factor 2 therefore represents areas where education, health, agriculture, transportation and communication activities are dominant. This factor is called research institution employment centre because it has very high component loading on education and health variables. Factor 3 is positively associated with agriculture and manufacturing industries and obviously represents peripheral areas where manufacturing and agricultural activities co-locate. Factor 3 is therefore named agricultural and manufacturing mixed job centre.

Table 3. Rotated component matrix from factor analysis

\begin{tabular}{lccc}
\hline \multirow{2}{*}{ Variables } & \multicolumn{3}{c}{ Component } \\
\cline { 2 - 4 } & 1 & 2 & 3 \\
\hline Agriculture & & 0.277 & $\mathbf{0 . 6 9 0}$ \\
Manufacturing industry & & & $\mathbf{0 . 9 3 6}$ \\
Health & 0.327 & $\mathbf{0 . 9 4 1}$ & \\
Government & $\mathbf{0 . 9 9 5}$ & & \\
Transportation and Communication & 0.641 & 0.245 & \\
Banking and insurance & $\mathbf{0 . 9 8 1}$ & & \\
wholesale and retail & $\mathbf{0 . 9 6 3}$ & & \\
Education & & $\mathbf{0 . 9 6 7}$ & \\
Services & $\mathbf{0 . 9 3 5}$ & & \\
\hline
\end{tabular}

Note: Component loadings with absolute values less than 0.2 are not shown and the values in bold indicates very high loadings. 
To identify significant employment centres that correspond to each factor, the three factor scores then entered into the hot-spot analysis. This is achieved with a spatial contiguity (first order) weight matrix. The hot-spot analysis was calculated and mapped with the ArcMap-ArcInfo extension under the spatial statistics tools in the ArcTool box. Hot-spot analysis result for $\mathrm{Gi}^{*} 1.96$ for the significant factors are presented in Figure 4. The hot-spot analysis shows that clusters in 6 neigbourhoods returned very high $\mathrm{Gi}^{*}>2.58$ and are significant at 0.01 . These neigbourhoods are Urubi, New Benin market $/ 3^{\text {rd }}$ cemetery, Ogboka/Ogbelaka, Iwegie, Ibiwe and Ugbowo with $\mathrm{Gi}^{*}$ scores of $3.30,3.02,3.01,3.06,3.03$ and 2.88 respectively.

Factor analysis reveals that the heterogeneous job centre is highly significantly associated with centralised higher order services. 5 significant clusters of factor 1 were found returning high $\mathrm{Gi}^{*}$ score of $>2.58$, while 2 returned $\mathrm{Gi}^{*}$ score $>1.96$. This result is confirmed by the commercial triangle at Ibiwe, Urubi and New Benin market, where a variety of trading activities are clustered; Iwegie, where financial industries are highly co-located with trading activities; Ogboka/Ogbelaka, where government jobs are highly co-located with service, health and financial industries. The result confirms dominance of the core centre as the location of tertiary employment sector. Factor 2 represents areas of co-location of health, education, agriculture, transportation and communication employments. The Ugbowo neigbourhood had significantly high $\mathrm{Gi}^{*}$ score of $>2.58$ on factor 2 . This is where the two most prominent research institutions in the region are located. These institutions are the University of Benin and the University of Benin Teaching Hospital. Other areas with significant Gi ${ }^{*}$ scores of $>$ 1.96 in factor 2 include Uselu and Ekosodin-Iduowinna neigbourhoods. To a lesser extent, factor 2 is also associated with agricultural industries that were identified at the inner part of Ekosodin-Iduowinna. The presence of pockets of transportation industry along Uselu, Silverbird broadcasting house along Nova road in Uselu and the Independent Television broadcasting house at Iguosa confirms the result of positive association of transportation and communication industries with factor 2 .

Hot-spot analysis for factor 3 revealed an important component and clustering pattern in BMR. The pattern shows a high positive association and co-location of manufacturing and agricultural jobs along trunk corridor roads connecting to the urban core centre. These clusters found returning Gi ${ }^{*}$ scores of $>1.96$ (Figure 4) were detected within the northeast (Ikpoba-Aduwawa) and the southeast (Sakponba-Sapele Road) PZs. The result shown in the northeast zone is confirmed by manufacturing industries such as Guinness brewery, Bendel brewery, paper milling, rubber processing and some minor palm oil and soap manufacturing industries all located within Oregbeni area. Some rubber processing and aluminum manufacturing industries located within Aduwawa area also confirmed the result of the hot-spot analysis. The $\mathrm{Gi}^{*}$ statistical analysis also detected significant clusters of agricultural activities in this zone; these were confirmed by the intense farming activities found around the semi-rural communities of Ohovwe and Ikhueniro along Benin-Agbor road and Idokpa along Benin-Auchi road. Hot-spot analysis of factor 3 found in the southeast PZ were confirmed by the bottling and aluminum companies along Sapele road, NPDC oil drilling plants, Brokars food processing and other minor manufacturing industries such as Austin-Laz manufacturing company and packet water companies located around Evboriaria industrial layout. The clusters of agricultural jobs in this zone detected by hot-spot analysis were confirmed by the presence of pig rearing and crop farming in Oka and numerous private farms along the upper part of Sapele and Sakponba roads.

Next, the significant clusters for the factors are named as follows: factor 1 which delineates the core centre is named heterogeneous job centre (higher services centre). Factor 2 which depicts the northwest PZ (Ugbowo-Ogida) is named research institution job centre. Factor 3 is used to delineate the northeast (Ikpoba-Aduwawa) and Southeast (Sakponba-Sapele road) peripheral zone and these were named manufacturing and agricultural mixed employment centres (Figure 5). 


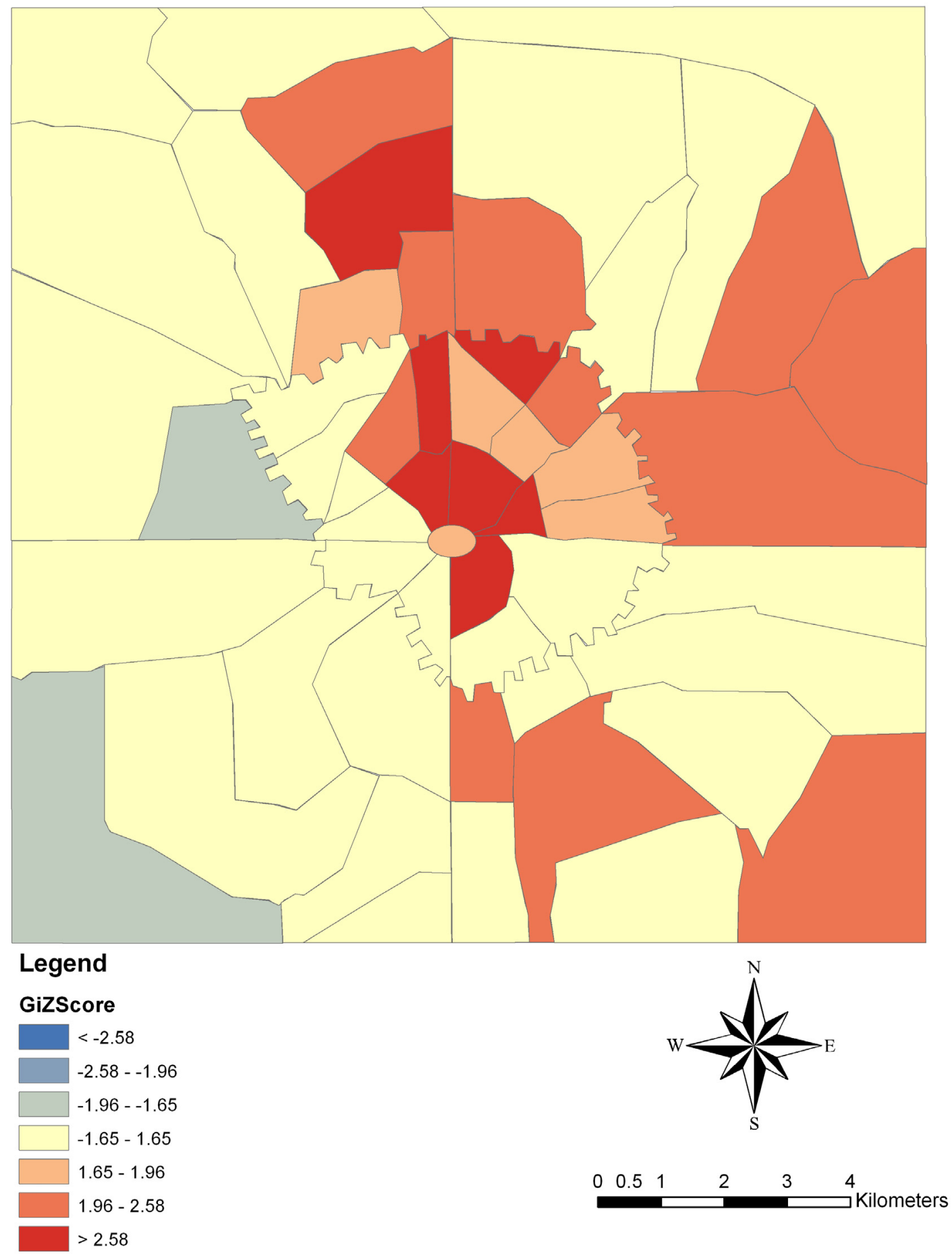

Figure 4. Significant local Getis-Ord statistic of Benin metropolitan region for factor 1-3 Note: this map is an overlay of the three hot-spot analyses pertaining to the retained factors. 

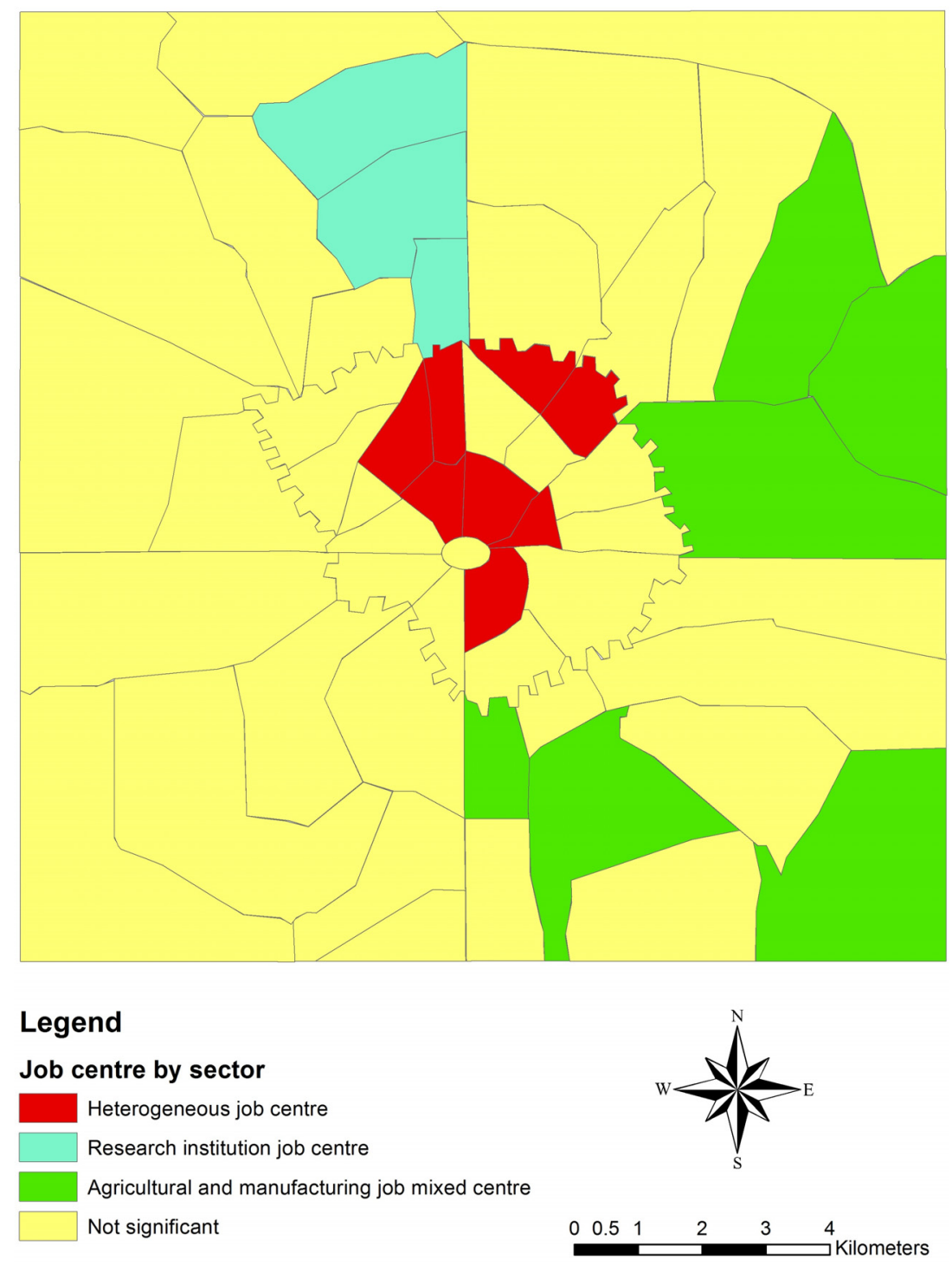

Figure 5. Employment centres of Benin metropolitan region by job industry categories

However, a few clusters of factor 1 detected in Aduwawa and Oregbeni neigbourhoods, Ikpokpan and Idumuivbioto areas in the northeast and southeast peripheral zone were blended to factor 3 . In the same manner, a few clusters of factor 1 found in Uselu and Ekosodin/Iduowinna areas in the northwest peripheral zone were blended to factor 2 . The justification for these blending is because the study region exhibits a complex land-use system. It is hard to find absolute clustering of a particular factor in one location. The result of the factor analysis and hot-spot analysis revealed that there are significant clusters of employment in the core centre, the northeast, northwest and southeast peripheral zones. Furthermore, the two employment centres detected in the northwest peripheral zone (Uselu and Ekosodin/Iduowinna) were blended to the Ugbowo employment centre as part of the research institution employment centre. This is because they lie contiguously adjacent to the Ugbowo employment centre.

\subsection{Effect of Employment Dispersal on Commute Mode and Travel Distance}

A binary logit model was used to estimate the main effect of job decentralisation on the choice of commuting mode. The variables used are the identified employment clusters, individual kilometre travel (IKT), the preferred commuting mode (PCM) and socio-economic variables (age, gender, income and car ownership). The model utilised PCM as the criterion variable, while the IKT and the identified employment clusters were included as the explanatory variables. Individual-level socio-economic variables were included to account for their influence. The PCM considered in the model are private means of travel and public transport. The employment clusters and 
IKT are used in the model as location variable to define job decentralisation. The result of the analysis is presented in Table 4.

The result shows that the variables of IKT and job location strongly prompt commuters to choose between the private and public mode of travel. The parametre estimate of the model reveals that short distance travel ranging from between $0-6 \mathrm{~km}$ significantly increases the likelihood of commuting by private means of transport. The Exponentiated $B(\operatorname{Exp} B)$ value associated with distance $(<1 \mathrm{~km})$ is 3.7 . Hence, when travel distance is raised by $1 \mathrm{~km}$ the odd ratio is about 3 times as large and therefore commuters are 3 times more likely to use private mode of transport. A careful inspection of this result (Exp B) shows that an additional increase in distance raised the odd ratio from 3.7 to 6.0 (which is an interval of approximately 3). From here, an additional increase dropped off the odd ratio to 3.0 (an interval of 3 from 6.0) and later to about 1.6. This means that distance ranging from less than a kilomtre to about $6 \mathrm{~km}$ encourages private mode dependence and longer distance of above $6 \mathrm{~km}$ discourages private mode dependence and encourages the use of public transport. With respect to employment cluster categories, concentralisation of jobs in the core centre decreases the likelihood of commuting by private mode and increases the likelihood of using public transport. In the employment location variable the Exp B value for heterogeneous job centre is 0.690 (this value is less than 1, therefore it decreases the odd ratio). This reveals that employment clusters in the urban core decreases the tendency of using private mode and increases the tendency of using public transport. The clusters in the peripheral employment centres (research institution job centre and agricultural and manufacturing job mixed centre) increase the probability of using private means of travel. The model also shows that high income commuters (earning up to $\$ 81000$ and $\$ 110000$ monthly) that falls within 25-45 years of age and owning at less a car increases the likelihood of commuting by private mode.

The influence of private transport also extended to the agricultural and manufacturing mixed job centre. An interesting aspect of this result is the proportionate share of the PCM that occurs in the employment centres. The employment clusters found in the CBD shows dominance of public mode of travel and long distance commute.

Table 4. Binary logit model of commuting mode choice

\begin{tabular}{|c|c|c|c|c|c|}
\hline Variables & $\mathrm{B}$ & Std. Error & Wald & Df & $\operatorname{Exp}(B)$ \\
\hline Age $(<25 \mathrm{yrs})$ & 0.379 & 0.248 & 2.344 & 1 & 1.461 \\
\hline Age (25-45yrs) & $0.418^{* *}$ & 0.198 & 4.468 & 1 & 1.519 \\
\hline Age (46-65yrs) & -0.127 & 0.195 & 0.426 & 1 & 0.881 \\
\hline Age $(>65 \mathrm{yrs})$ & & & 14.764 & 3 & \\
\hline Gender (male) & 0.027 & 0.141 & 0.037 & 1 & 1.027 \\
\hline Income $(<\mathbb{N} 50,000)$ & $-2.809 * *$ & 0.217 & 168.041 & 1 & 0.060 \\
\hline Income ( $\$ 51,000-80,000)$ & $-1.789 * *$ & 0.193 & 85.653 & 1 & 0.167 \\
\hline Income ( $\$ 81,000-110,000)$ & $0.825^{* *}$ & 0.190 & 18.886 & 1 & 2.938 \\
\hline Income $(>\$ 110,000)$ & & & 203.112 & 3 & \\
\hline Car ownership (yes) & $1.990^{* *}$ & 0.131 & 229.271 & 1 & 7.318 \\
\hline Employment location ${ }^{1}$ & $-0.37 * *$ & 0.146 & 6.485 & 1 & 0.690 \\
\hline Employment location ${ }^{2}$ & 0.192 & 0.161 & 1.416 & 1 & 1.211 \\
\hline Employment location ${ }^{3}$ & & & 21.084 & 2 & \\
\hline Travel distance $(<1 \mathrm{~km})$ & $1.335^{* *}$ & 0.240 & 30.944 & 1 & 3.799 \\
\hline Travel distance $(1-3 \mathrm{~km})$ & $1.798^{* *}$ & 0.229 & 61.670 & 1 & 6.038 \\
\hline Travel distance (4-6km) & $1.110^{* *}$ & 0.234 & 22.501 & 1 & 3.035 \\
\hline Travel distance $(7-9 \mathrm{~km})$ & 0.495 & 0.260 & 3.410 & 1 & 1.693 \\
\hline Travel distance $(>10 \mathrm{~km})$ & & & 65.184 & 4 & \\
\hline Constant & $-1.407 * *$ & 0.349 & 16.250 & 1 & 0.245 \\
\hline
\end{tabular}

$-2 \log$ likelihood $=1512.353 ;$ Pseudo $R^{2}=0.498 ; X^{2}=11.175 ;$ No. $=1706$

**Significant parameter at the 0.05 level; ${ }^{1}$ Heterogeneous job centre; ${ }^{2}$ Research institution centre; ${ }^{3}$ Agricultural and manufacturing job mixed centre; $\$$ represents the Nigeria Naira. 
This means that transit performance is high at a higher degree of centralisation. The primacy of private mode of journey to work travel over short distances in other sub-centres provides an insight into the link between job dispersal and reduced commuting length.

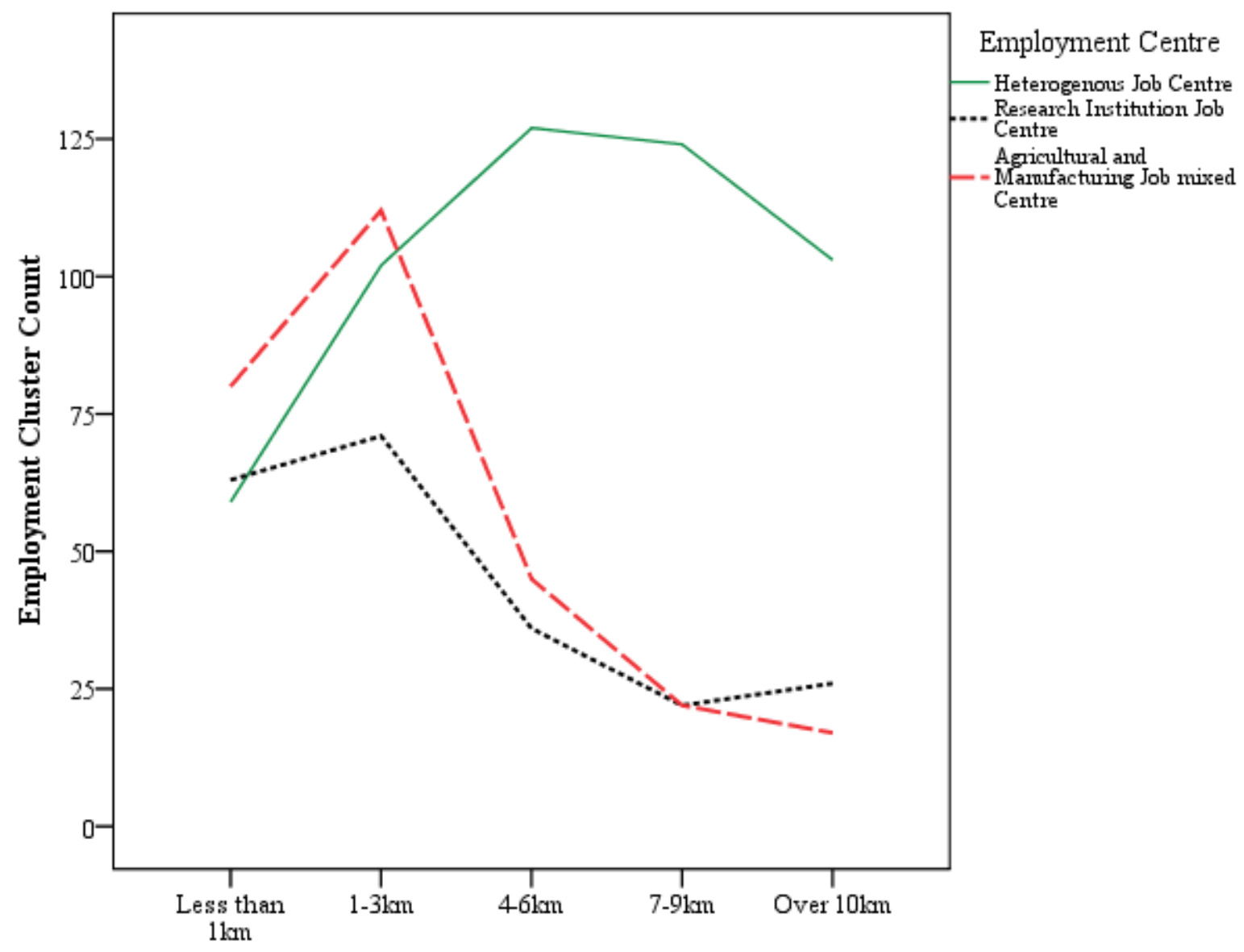

Individual Kilometre Travel

Figure 9. Commuting distance by employment centres

Taking the distance variable into consideration, there is high probability that the commuting distance to heterogeneous job centre (clusters in the CBD) is longer compared with other sub-centres (Figure 9). In Figure 9, the overall commute to the various classes of employment centres are plotted against IKT. The result of this plot shows the importance of commute distance in defining employment spatial structure based on the existing theories. However, it is expected that the positive relationship between employment dispersal and journey to work distance becomes weaker as the number of sub-centres increases. This expectation is confirmed by the interpretation of the plot. The plot shows that the emergence of sub-centres has resulted to a substantial reduction (of about 20 percent) in commuting distance. The heterogeneous job centre in the CBD exhibit high double travel peaks and these are the 4-6 km and 7-9 km categories of IKT. The research institution job centre and the agricultural and manufacturing mixed job centre both exhibits their travel peaks at the $1-3 \mathrm{~km}$ category of IKT.

\subsection{Effect of Employment Decentralisation on Commute Times}

A multiple regression model was used to examine the influence of employment spatial configuration on commute times in BMR. The inclusion of commuting mode choice as explanatory variable is to avoid misspecification error, because as noted by Schwanen et al. (2004) the mode of travel may have significant influence on travel times. As stated in the previous section, employment cluster and commuting distance are used to define job location variable. The result of the regression model is presented in Table 5.

Employment cluster parametres exhibits a strong negative association with travel times (it returned a coefficient value of -14.237). The model shows that there is a tendency for travel times to reduce by an estimated 14 
minutes when commuting is destined outside the urban core. As expected, travel distance exhibits a strong positive association with travel times (coefficient value is 7.870 ). This means that $1 \mathrm{~km}$ increase in travel distance would lead to an estimated 7.9 minutes increase in travel times. Unexpectedly, the PCM variable did not significantly influence commuting times.

Table 4. Regression result for employment decentralisation and travel times

\begin{tabular}{lccc}
\hline Variables & Coefficients & Standard error & t-stat \\
\hline Constant & $52.377^{* *}$ & 4.724 & 11.088 \\
Employment cluster & $-14.237 * *$ & 2.098 & -6.787 \\
Commuting distance $(\mathrm{km})$ & $7.870^{* *}$ & 1.825 & 4.313 \\
Preferred commuting mode & 14.296 & 7.129 & 2.005 \\
$R^{2}=0.793 ; F=12.854$ & & & \\
\hline
\end{tabular}

** Significant parametre at the 0.05 level.

Overall, job location variable shows strong positive and negative effects on travel times in the region. The inclusion of these variables raised the model's fitness to $\left(\mathrm{R}^{2}\right.$ value $\left.=0.793\right) 79.3$ percent explained.

\section{Conclusion}

This study has shown that BMR exhibits a dominant employment centre which is the zone of heterogeneous job industries and higher order services. The heterogeneous job centre holds almost half of the total jobs in the metropolis and above all, 85.6 percent are within the tertiary job industry category. Factor analysis and hot-spot analysis were adopted for identification of vital components of the spatial structure of employment in the study region. The method is specifically and systematically designed to extract significant clusters.

Interestingly, the binomial logit models have shown that the employment spatial structure exert significant influence on all dimensions of commuting pattern of BMR. It was discovered that decentralisation of jobs in the metropolis has led to a reduction in commute times and distance. This finding is consistent with the results of Gordon et al. (1998); Giuliano and Small (1993); Crane and Chatman (2003); Izraeli and McCarthy (1985). The binary logit model revealed the existence of dichotomy in the travel distance of commuters. On the one hand, short distance travel of less than $1 \mathrm{~km}-6 \mathrm{~km}$ was identified and the private mode of transport shows dominance over such distance. On the other hand, long distance travel ranging from $7 \mathrm{~km}$-over $10 \mathrm{~km}$ was identified and the public travel mode is preferred over this distance. Specifically, the analysis of the modal split suggests that employment location strongly affect the modal choice of commuters in the region. The emerging pattern for BMR (as expected) is that public transit performance is higher at a lesser degree of decentralisation. This finding is consistent with predictions made by the monocentric model of metropolitan evolution, especially as modified to recognise the emergence of sub-centres (Izraeli \& McCarthy, 1985; Schwanen et al., 2001).

The regression result for commuting times produced a slightly odd upshot with concern to the factors influencing commuting duration. It suggests that in the region, modal split cannot significantly explain the variation in travel times across the classes of employment centres. However, it was discovered that the spatial distribution of job clusters and travel distance are the main forces influencing journey to work duration. This finding is partly at odds with the conclusion of Schwanen et al. (2004) who discovered that only the spatial extension of the metropolitan region of the Netherlands is relevant to the explanation of variation in commuting times. With respect to the current debate on urban spatial structure and commuting behaviour articulated in the literature review, the key findings of this paper shows that like most cities of advanced countries, African cities are evolving from purely monocentric to polycentric urban configuration. The effect of this change has led to a reduction in travel time and distance. This findings support the co-location hypothesis originally proposed by Gordon et al. (1998).

Basically, the findings of this paper point to the fact that BMR is neither purely a monocentric nor essentially a polycentric urban region. The morphological pattern and the spatial arrangement of the identified sub-centres along mono-directional trunk corridor roads leading to the urban core confirm the existence of strong monocentric characteristics. Notwithstanding, the sub-centres equally exhibited strong polycentric characteristics In relation to other documented evidence, the findings of this paper present a reasonable level confidence and 
beside this, field survey and verification confirmed the emergence of the urban spatial configuration highlighted in the research findings.

For policy and planning purposes, BMR is undergoing a gradual transition process from monocentric to polycentric urban configuration. This process makes the region a complex structure especially for urban planners. However, these findings suggest that prescriptions of higher degrees of self-sufficiency in new peripheral job centres are more likely to reduce commuting duration and distance. The uniqueness of the region's spatial structure presents a framework of robust influence with regard to creating a reasonable level of balance in the modal split as it relate to travel distance. It is therefore recommended that the identified dichotomy in travel distances (in relation to public vs private mode) should be encouraged and adopted as a strategic plan for sustainable urban traffic development. The implication is that the preference of public mode over private mode in long distance corridor travel, increases transit performance by reducing cost of travel and congestion. This will help checkmate the fundamental pitfall of job decentralisation which involves the heavy dependence on private mode for both long and short distance commute. Consequently, this will initiate heavy congestion and raise the demand and usage of fossil fuel. The planning authorities of BMR have recently taken a rather lukewarm and mediocre approach towards decentralisation by relocating bus terminals from the Ring Road area (CBD) to less congested areas within the urban core. More effective approach of decentralisation and polycentric development (which have been adopted by many developed nations) should be introduced into the region's planning strategy. Such approach includes establishing developmental activities in the identified sub-centres and relocating major government offices from the urban core to the peripheral centres. Spatial policy framework that will discourage private firms from locating their activities in the urban core should be formulated. This may likely force business activities to concentrate in the edge of the city and as a result labour may move closer to their workplaces. In addition, since most of the new employment activities will occur in the edge of the city, planners and decision makers of BMR should make concerted effort towards preparing comprehensive developmental plans for the whole dimension of the sub-urban regions. Such plans among others should include; sustainable and suitable environment for residential development, constructing good road network (such as ring roads in strategic locations), provide security and market spaces.

In order to widen the empirical basis to allow for more universal conclusions in the region's land use and travel perspective, additional researches are needed on the relationship between travel modes and travel times, employment centre identification, the influence of the region's mono-directional corridor road network on travel. It is pertinent for the state government and other stake-holders to fund such researches so as to allow for the selection of larger sample size and more neighbourhoods since the available national census data is not adequate.

\section{References}

Aguilera, A., \& Mignot, D. (2004). Urban sprawl polycentrism and commuting: A comparison of seven French urban areas. Urban Public Economics Review, 1, 93-113.

Alpkokin, P., Black, J., Hayashi, Y., \& Gercek, H. (2005). Polycentric employment growth impacts on urban commuting patterns: Case study of Istanbul. Journal of the Eastern Asia Society for Transportation Studies, 6, 3835-3850.

Alpkokin, P., Cheung, C., Black, J., \& Hayashi, Y. (2008). Dynamics of clustered employment growth and its impacts on commuting patterns in rapidly developing cities. Transportation A, 42, 427-444.

Anas, A., Arnott, R., \& Small, K. A. (1998). Urban spatial structure. Journal of Economic Literature, 26, 1426-1464.

Anselin, L. (1995). Local indicators of spatial association-LISA. Geographical Analysis, 27(2), 93-115. http://dx.doi.org/10.1111/j.1538-4632.1995.tb00338.x

Baumont, C., Ertur, C., \& LeGallo, J. (2004). Spatial analysis of employment and population density: The case of the agglomeration of Dijon 1999. Geographical Analysis, 36(2), 146-176. http://dx.doi.org/10.1111/j.1538-4632.2004.tb01130.x

Bollote, L. (1991). Transport in Paris and the Ilede France. Built Environment, 17, 160-171.

Cervero, R. (1996). Jobs-housing balance revisited: trends and impacts in the San Francisco Bay area. Journal of American Planning Association, 62, 492-511. http://dx.doi.org/10.1080/01944369608975714

Cervero, R., \& Landis, J. (1992). Suburbanization of jobs and the journey to work: a submarket analysis of commuting in the San Francisco Bay area. Journal of Advance Transport, 25, 275-297. http://dx.doi.org/10.1002/atr.5670260305 
Cervero, R., \& Wu, K. L. (1998). Sub-centring and commuting: Evidence from the San Francisco Bay area 1980-1990. Urban Studies, 35(7), 1059-1076. http://dx.doi.org/10.1080/0042098984484

Crane, R., \& Chatman, D. G. (2003). As jobs sprawl, whither the commuting? Access, 23, 14-19.

Daniel, M. (1973). Conditional logit analysis of qualitative choice behaviour. In P. Zarembka (eds), Frontiers in Econometrics (pp. 105-142). New York: Academic press.

Dubin, R. (1991). Commuting patterns and firm decentralisation. Land Economics, 67(1), 15-29. http://dx.doi.org/10.2307/3146482

Ewing, R. (1997). Is Los Angeles-style sprawl desirable? Journal of American Planning Association, 63, 107-126. http://dx.doi.org/10.1080/01944369708975728

Field, A. (2005). Discovering statistics using SPSS. London: SAGE Publications Ltd.

Giuliano, G., \& Small, K. A. (1991). Sub-centres in the Los Angeles region. Regional Science and Urban Economics, 21, 163-182. http://dx.doi.org/10.1016/0166-0462(91)90032-I

Giuliano, G., \& Small, K. A. (1993). Is the journey-to-work explained by urban structure? Urban Studies, 30, 1485-1500. http://dx.doi.org/10.1080/00420989320081461

Gordon, P., \& Wong, H. L. (1985). The cost of urban sprawl: some new evidence. Environmental Planning Association, 17, 661-666. http://dx.doi.org/10.1068/a170661

Gordon, P., Kumar, A., \& Richardson, H. W. (1989). The influence of metropolitan structure on commuting times. Journal of Urban Economics, 26(2), 138-151. http://dx.doi.org/10.1016/0094-1190(89)90013-2

Gordon, P., Richardson, H. W., \& Jun, M. J. (1991). The commuting paradox: evidence from the top twenty. Journal of the American Planning Association, 57, 416-420. http://dx.doi.org/10.1080/01944369108975516

Guoqiang, S., \& Wang, J. (2012). A freight mode choice analysis using a binary logit model and GIS: The case of cereal grains transportation in the United States. Journal of Transportation Technologies, 2, 175-188. http://dx.doi.org/10.4236/jtts.2012.22019

Guth, D., Holz-Rau, C., \& Maciolek, M. (2009). Employment suburbanisation and commuter traffic in German city regions, Proceedings of the $9^{\text {th }}$ Swiss Transport Research Conference, Monte Verita,Ascona.

Hakim, I., \& Parolin, B. (2009). Spatial structure and spatial impacts of the Jakarta metropolitan area: A Southeast Asian EMR perspective. International Journal of Human and Social Science, 4(2) 397-405.

Ham, M. V., Hooimeijer, P., \& Mulder, C. H. (2001). Urban form and job access: Disparate realities in the Randstad. TijdschriftvoorEconomische en SocialeGeografie, 92(2), 231-246. http://dx.doi.org/10.1111/1467-9663.00152

Izraeli, O., \& McCarthy, T. R. (1985). Variation in travel distance, travel time and model choice among SMSAs. Journal of Transport Economics and Policy, 19(2), 139-160.

Kitamura, R., Susilo, Y. O., Fukui, K., Murakami, J., \& Kishino, K. (2003). The invariants of travel behaviour: the case of Kyoto-Osaka-Kobe metropolitan area of Japan, 1970-2000. Paper presented at the $10^{\text {th }}$ Conference of the International Association for travel Behaviour Research, Lucerne.

Levinson, D. M., \& Kumar, A. (1994). The rational locator: why travel times have remained stable. Journal of the American Planning Association, 60, 319-332. http://dx.doi.org/10.1080/01944369408975590

McMillen, D. P. (2001). Polycentric urban structure: The case of Milwaukee. Economic Perspectives, 2, 15-27.

Miklius, W., Casavant, K. L. \& Garrod, P. V. (1976). Estimation of demand for transportation of agricultural commodities. American Journal of Agricultural Economics, 58(2), 217-223. http://dx.doi.org/10.2307/1238972

Muley, D., Bunker, J., \& Ferreira, L. (2009). Investigation into travel modes of TOD users: Impacts of personal and transit characteristics. International Journal of Its Research, 7(1), 3-13.

Newman, P. W. G., \& Kenworthy, J. R. (1989). Gasoline consumption and cities: A comparison of US cities in a global survey. Journal of American Planning Association, 55, 24-36. http://dx.doi.org/10.1080/01944368908975398

Nkeki, F. N. (2010). A study of the formidability of GIS-based system as an indispensable tool for solid wastes management: A case study of Benin metropolitan region. Benin Journal of Social Sciences, 18(1\&2), 195-208. 
Onokerhoraye, A. G. (1978). The spatial pattern of residential districts in Benin, Nigeria. Urban Studies, 14(3), 291-302. http://dx.doi.org/10.1080/00420987720080631

Ord, J. K., \& Getis, A. (1995). Local spatial autocorrelation statistics: Distribution issues and an application. Geographical Analysis, 27, 286-306. http://dx.doi.org/10.1111/j.1538-4632.1995.tb00912.x

Parolin, B. (2006). Employment centres and the journey to work in Sydney: 1981-2001. In proceedings, State of Australian cities 2nd National conference, eds Brisbane (Australian), 1-15.

Rodriguez-Gamez, L. I., \& Dall'erba, S. (2012). Spatial distribution of employment in Hermosillo, 1999-2004. Urban Studies, 49(16), 3663-3678. http://dx.doi.org/10.1177/0042098012448552

Rogerson, P. A. (2001). Statistical methods for geography. London: SAGE Publications Ltd.

Schwanen, T., Dieleman, F. M., \& Dijst, M. (2001). Travel behavior in Dutch monocentric and polycentric urban systems. Journal of Transport Geography, 9(3), 173-186. http://dx.doi.org/10.1016/S0966-6923(01)00009-6

Schwanen, T., Dieleman, F. M., \& Dijst, M. (2003). Car use in Netherlands daily urban systems: does polycentrism result in lower commuting time? Urban Studies, 24, 410-430.

Schwanen, T., Dieleman, F. M., \& Dijst, M. (2004). The impact of metropolitan structure on commute behaviour in the Netherlands: A multilevel approach. Growth and Change, 35, 304-333. http://dx.doi.org/10.1111/j.1468-2257.2004.00251.x

Snellen, D., Hilbers, H., \& Hendriks, A. (2005). New housing developments on the go: an analysis of the vinex spatial mobility policy, Ruintelijk Planbureau. Rotterdam: NAi Uitgevers.

Susilo, O. Y., \& Maat, K. (2007). The influence of built environment to the trends in commuting journeys in the Netherlands. Transportation, 34, 589-609. http://dx.doi.org/10.1007/s11116-007-9129-5

Yang, J. (2005). Commuting impacts of spatial decentralisation: a comparison of Atlanta and Boston. Journal of Regional Analysis and Policy, 35(1), 69-78. 